\title{
Em Bali, homens usam flores na orelha: protocolo de uma experiência com o Topeng Pajegan
}

Felisberto Sabino da Costa

\section{Resumo}

Este artigo teve como objetivo refletir sobre o trabalho com a máscara, a partir de experiências realizadas com o Topeng, em Bali, na Indonésia, apontando alguns princípios fundamentais.

Palavras-chave: máscara, atuação, treinamento, Topeng.

\section{Abstract}

This article aimed at reflecting on mask work, based on experiments with Topeng in Bali (Indonesia), pointing out some fundamental principles.

Keywords: mask, performance, training, Topeng.

O teatro, a dança e a música, em Bali, compõem uma paisagem que se integra à vida sociorreligiosa da população e se renova constantemente. Alteridade que se manifesta na labuta cotidiana, na qual a tradição é algo que se mantém em seu transitar. Nesse universo insular, no qual o secular, o sobrenatural e o religioso não desenham uma linha fortemente demarcada, como observa Eisemam (1995, p. 208), surgem manifestações artísticas que se alimentam das tradições e dos contextos sociais e religiosos em que elas se inserem. Pode-se citar, por exemplo, as danças kebyar-duduk e trompomg ${ }^{1}$, criadas pelo dançarino e coreógrafo I Ketut Mario, nos anos 1930, nas quais a primeira tem como característica principal o fato de o artista dançar sentado no chão, de pernas cruzadas. A segunda é uma dança que envolve corpo e objeto, na qual Mario, ao tocar o tronpomg, exercita sua destreza corporal lançando as duas varetas em diversas direções.

O Drama Gong sofre um grande impulso nos anos 1960, quando surge como resultado da mistura de tradições artísticas balinesas e elementos do teatro ocidental.

\footnotetext{
${ }^{1}$ Em Balinês, Duduk significa sentado. Trompong é um instrumento da orquestra Gamelan, composto por uma série de cubas metálicas emborcadas, dispostas uma ao lado da outra e que são tocadas com duas varetas. Kebyar é uma orquestra Gamelan marcada por um ritmo vibrante, geralmente, formada por 25 músicos.
} 
É também acompanhado por um gamelan kebyar, cujo último termo traz como um de seus possíveis significados 'o processo de floração'. A estrutura cênica organiza-se em explosões de ritmos e efeitos sonoros, espontaneidade e improvisação dos atores, em que os figurinos dialogam com as roupas cotidianas utilizadas pela população. Dramaturgicamente estruturado com personagens tipos narrativas tradicionais da cultura balinesa, como as de Panji (Malat) e outras que incorporam temáticas contemporâneas provenientes do desejo grupal, o Drama Gong, em geral, não utiliza máscara, porém, a maquiagem se evidencia como uma segunda pele (máscara) do ator.

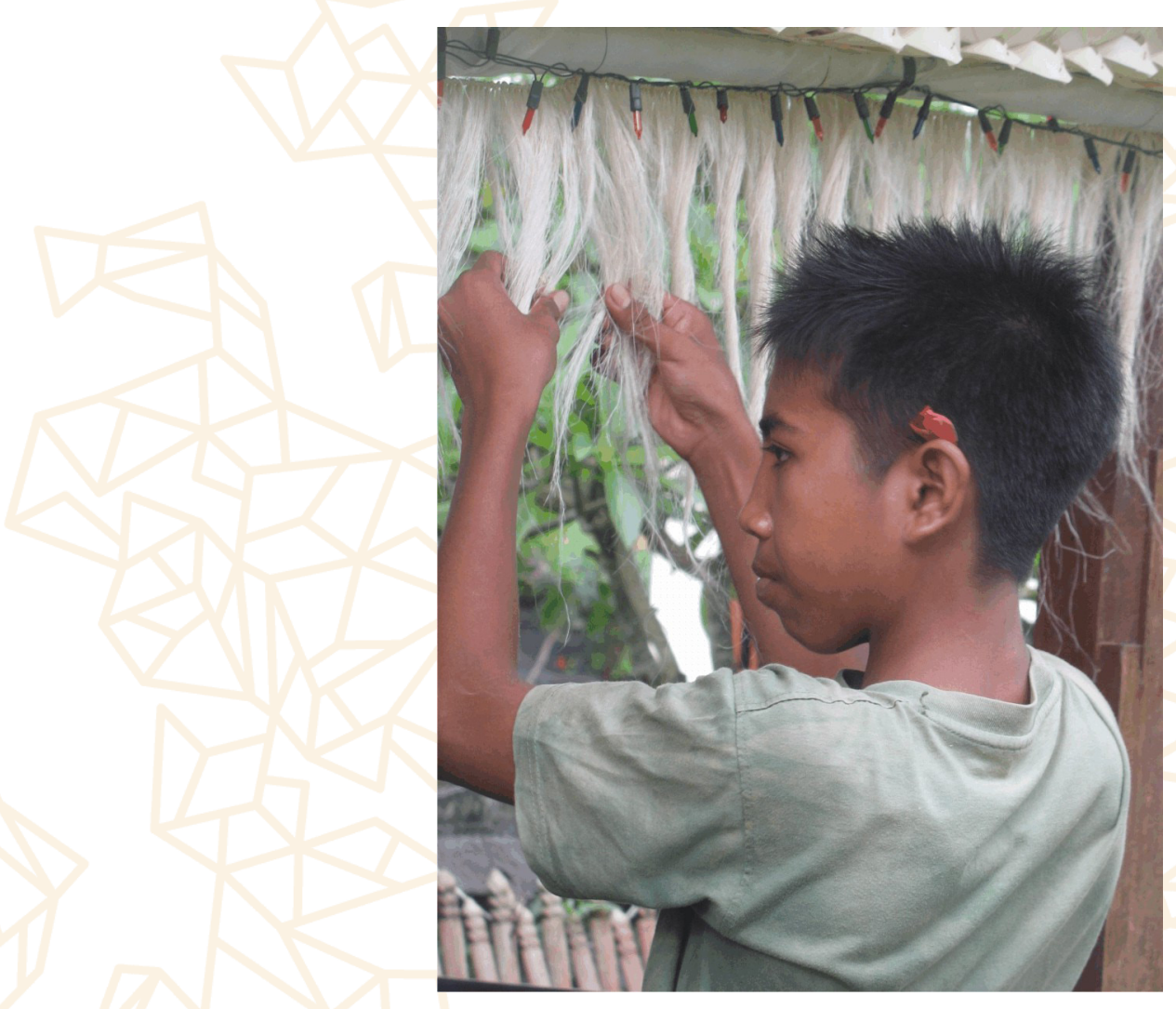

Este artigo enfocou uma experiência com a máscara balinesa vivida com o mestre I Made Djimat, em Batuan, e não teve como pretensão explicar o Topeng, mas refletir sobre uma experiência vivida em meu corpo, ou seja, de como o Topeng reverberou em mim e deixou suas 'memórias' afetivas, no sentido precípuo de ser afetado. Afeto esse que diz respeito também ao que foi visto, principalmente, durante as apresentações nos templos. Para tanto, mergulhei nesse fazer imbuído do conceito de neutralidade, tal como propõe Lecoq (1997), ao elaborar a pedagogia da máscara neutra: age sem articulação com o passado ou o futuro, entregando-se inteiramente ao momento de sua eclosão. Assim, o que importa é a experiência vivida no presente. É ainda possível relacionar essa disposição inicial ao conceito balinês de pelinggih, que se refere ao lugar limpo para que os ancestrais 
convidados se instalem durante certo tempo e depois partam. Desse modo, meu corpo neutro/asseado, tornou-se o espaço/assento para receber a visita de um estrangeiro - a potência máscara. Assento que acolhe o corpo, modifica-o e é modificado no ato, como se dissesse: "eis o meu corpo, faça dele a sua morada". Ainda, como nas alterosas, aquele que recebe uma visita acolhe o dom que ela traz, retribuindo com uma boa conversa, bolo, pão de queijo e um cafezinho². Assim, o registro da experiência concentra-se no seu aspecto cênico-atoral, que, apesar de estar impregnado de suas origens sociorreligiosas não há como escapar! -, não constituiu o foco central do meu desejo. De igual modo, não me detenho no transe que pode advir com o uso da máscara. No treinamento, é possível ultrapassar a esfera psicofísica e atingir a dimensão espiritual, porém, tal como a flor nos ensinamentos descritos por Zeami, há um tempo a ser nutrido para que a parte mais apurada dessa substância possa se assentar no coração. Essa busca é uma escolha ou um chamado que alguns se predispõem a acolher, pois "a dimensão espiritual da atuação não se coloca para todo mundo" (OLSEN, 2004, p. 20). No teatro balinês, notadamente quando acontece nos templos, a atuação revela sua dimensão espiritual, e percebe-se nela que se deve trilhar um caminho.

O termo Topeng significa máscara, mas pode ser compreendido também como evento-máscara, o acontecimento cênico que se apresenta como Topeng Panca ${ }^{3}$, realizado por cinco atores-dançarinos, e Topeng Pajegan, configurado como espetáculo solo, em que o ator-dançarino faz vários personagens. A flexibilidade, como diz Cokorda Swastika ${ }^{4}$, não é estranha à cultura do balinês em seu viver diário e, dessa forma, o acontecer da vida se abre para as contingências que interferem nas ações e podem afetar o estabelecido. Isso diz respeito, por exemplo, à sua relação com o tempo.

A constituição do Topeng Pajegan articula diversas camadas de improvisação, compreendendo as estruturas espetacular, dramatúrgica, atoral, entre outras. Assentada numa sequência estabelecida, essa estrutura é maleável e ocorre conforme o ator-dançarino adquire uma configuração particular quanto ao arranho das máscaras. Porém, há aquelas que são fundamentais nessa disposição, como, por exemplo, Topeng Tua (um velho), Topeng Keras (um homem vigoroso) ou Sidakharya, a figura que conclui o evento. No trabalho com Djimat, investiguei as duas primeiras máscaras

\footnotetext{
${ }^{2}$ Ofereço essa passagem à atriz e professora Daniela Perucci, uma companheira de jornada, durante a maior parte dos 45 dias em que permaneci em Bali, e que proporcionou aflorar a minha mineiridade.

${ }^{3}$ O Panca - 'cinco' em balinês - nem sempre é composto pela quantidade exata indicada.

${ }^{4}$ Professor, pesquisador, especialista em Gamelan. Entrevista concedida em Ubud, fevereiro de 2012.
} 
citadas, bem como os clowns Penasar (com olhos esbugalhados pintados) e Wijil (em duas feições distintas) e uma sequência de cinco bondres ${ }^{5}$, categoria de personagens cômicos, os quais, geralmente, pertencem à casta mais baixa.

A palavra pajegan traz em si a conformação do espetáculo. O termo paje refere-se à ambiência do mercado, ao ato de escolher os diversos produtos durante uma compra. Assim, eleger as máscaras para compor um solo implica escolher pelos sentidos, envolvendo cores, cheiros, tato, olfato e paladar. Há que considerar ainda o aspecto intuitivo que integra essa ação. Da mesma forma que a cesta pode ser composta por uma variedade de especiarias, a estrutura do Topeng Pajegan obedece a uma configuração na escolha e sucessão das máscaras que virão à cena, compondo uma pletora de imagens oferecidas ao público e às divindades. Dança, atuação, música e comicidade misturam-se aos aspectos sagrado e profano do acontecimento, alimentado pelas narrativas tradicionais, que não se encerram numa estrutura rígida. Em determinadas passagens, tornam-se porosas e esgarçam-se no espaço-tempo durante o contato com as pessoas. Por exemplo, a partitura do Topeng Tua traz aspectos que iluminam as dualidades - sério-cômico ou sagrado-profano - presentes na composição dessa dança. Se, por um lado, o velho manifesta aspectos pungentes quanto à decrepitude do corpo, por outro, traz o lado cômico que entremeia essa luta travada com o tempo. É nessa trilha que se constitui a passagem em que ele tenta matar um piolho. Em outros momentos, o velho reverencia o altar e a sombrinha que o protege, benze-se com as mãos em triângulo na altura do fígado, de onde emana a energia (bayu), e purifica-se com água e arroz. Há sequências de ações em cena, que são o reflexo do que ocorre nas ações, no templo, durante as cerimônias religiosas.

No Topeng Pajegan, o ator-dançarino utiliza máscaras inteiras, que podem ser articuladas ou fixas, meias-máscaras e acentos. Existem figuras compostas por máscaras inteiras rígidas que não falam, o que não implica um mutismo absoluto, pois a sonoridade se inscreve no corpo e é evidenciada por suas intensidades, movimentos e gestos. Há também os sons que provêm da interação com o Gamelan, referente não ao som gerado pela orquestra, mas àquele que brota da escuta entre o corpo desta última e o do atuante, resultando numa comunhão que se faz música. A fala é um atributo compo-

\footnotetext{
5 Entre os bondres, destacam-se os tipos que tive a oportunidade de experimentar e vê-los em ação, em apresentações de Djimat: Keta (em decorrência de um acidente de moto, apresenta dificuldades na fala e limitações físicas); Bongol (um homem quase surdo), Nyoman Semariani (uma mulher solteira); Nilu Cantereng (mulher que apresenta feições semelhantes à de Semariani, porém, no lugar do nariz, tem-se um orifício). Nilu é mais atrevida.
} 
sitivo dos penasares e dos bondres, tipos que se expressam em falares múltiplos, vozes da sociedade plasmadas em figuras por intermédio de meias-máscaras ou máscaras inteiras articuladas. Catra (2005) observa que Penasar atua como um mediador entre o mundo invisível dos deuses/espíritos e o visível do público, bem como entre o homem e seu meio ambiente. Em suas falas, canções e brincadeiras, Penasar congrega o bem e o mal, o passado e o presente, sagrado e profano e outros conceitos dialéticos que remetem às questões contemporâneas vivenciadas pelos espectadores.

O processo conduzido por Djimat ocorreu, fundamentalmente, pela repetição no sentido do acontecer novamente. Inicialmente, tive contato com a totalidade da partitura de movimentos e gestos das figuras introdutórias. No momento em que foi apresentado - Topeng Tua, houve uma espécie de caos interno, devido à complexidade da sequência, vista em sua inteireza. Quando partimos para pequenas células dessa partitura, avançamos em cumplicidade, alimentada pelas inúmeras repetições, traduzidas como o querer de novo. Aos poucos, o caos inicial foi se organizando na dança mostrada, delineando o personagem, um exercício de artesania, em que cada repetição do movimento era (in)corporado em filigranas e se fazendo corpo em meu corpo. A prática estimulada da repetição implicava em questões que iam além do aspecto psicofísico e abrangia domínios que transitam em outras dimensões, como, por exemplo, à que se endereça ao não-visível. Vale ainda ressaltar o espaço e o tempo em que aconteciam as práticas: a área retangular de um bale ${ }^{6}$, aberta em três lados. Quando começávamos, às seis horas, o sol ainda não havia nascido e o silêncio instaurado pela natureza promovia um estado de alerta, naquela atmosfera atravessada por sua polifonia. À tarde, o processo era repetido, no qual a luz e a temperatura eram outras, provocando sensações distintas e, tal como ressalta Storaro (2008), "a luz é uma fonte de energia que chega até nós ainda que não a busquemos, e altera o metabolismo, a pressão sanguínea e a emoção" (p. 4). Essa questão pode parecer de somenos importância, porém acredito que o espaço-tempo contamina a experiência e, dessa forma, não pode ser desconsiderado. A primeira ação do treino consistia em retirar esse espaço de seu uso cotidiano por intermédio de uma reverência em que conectávamos, com as mãos, o céu (alto) e a terra (baixo), sendo o corpo o elemento intermediário. Movimento que era repetido na finalização, como se dissesse "o trabalho foi feito" e liberasse o espaço a outras ocorrências diárias.

\footnotetext{
${ }^{6}$ Edificação característica da arquitetura balinesa, uma estrutura retangular ou quadrada e que geralmente apresenta um espaço aberto e coberto, contíguo.
} 


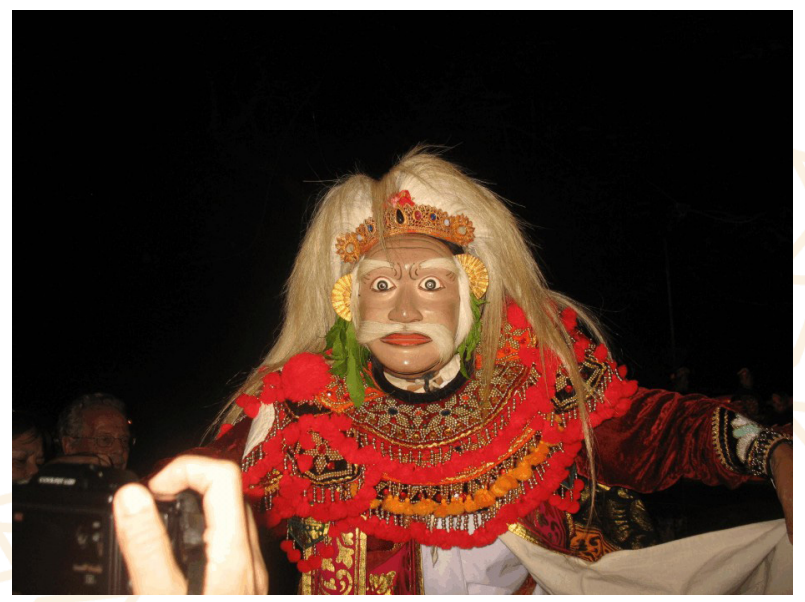

Topeng Tua

Do mesmo modo como aconteceu com o Topem Tua, o trabalho com o Topeng Keras e com alguns bondres consistiu, inicialmente, na exploração da partitura gestual de cada figura, sem a utilização da máscara, num processo de repetição similar ao descrito, ou seja, gerava-se uma energia interna que constituía o personagem. Com alguns outros bondres, mergulhamos, diretamente, na visualização imaginativa a partir da máscara, processo que se manifesta no encontro entre o ator e o objeto. As máscaras eram colocadas numa poltrona e tal como uma flor (ou fruta) disposta no mercado, que captura o olhar do observador ao mesmo tempo em que é capturada, a escolha envolve a atração que mescla algo da ordem do visível e do invisível. $\mathrm{Na}$ relação estabelecida com a máscara, sente-se sua aparência, sua cor e seu cheiro, percebe-se o movimento daquela feição e as intensidades ali instaladas. Por meio do objeto, estabelece-se um diálogo com o mascareiro, que perfaz, na máscara, as linhas e as direções energéticas para a composição de uma figura. Como observado por alguns mascareiros, sua parte interna é como um quarto que o rosto habita e deve constituir um espaço agradável. Tocar a máscara é descobrir o que ela nos diz e aquilo que desejamos dizer-Ihe, enfim, há um encontro de seres desejantes - ator e figura que se misturam em ato.

Conforme observava Djimat?, os bondres $^{8}$ trazem uma grande liberdade de criação fundada na imaginação e na improvisação. Vale ressaltar que a partitura fixa das máscaras introdutórias que estudamos, quando vistas em ação por dançarinos, em templos e em outros locais, resultava numa coreografia muito particular. Portanto, quando

\footnotetext{
${ }^{7}$ Depoimento colhido em conversa na vila de Batuan, fevereiro de 2012.

${ }^{8}$ Geralmente, os bondres são máscaras que têm seu lastro em tipos sociais da cultura balinesa.
} 
realizava a sua performance do Topeng Tua, Djimat mantinha a dinâmica, os gestos e os movimentos da figura, porém, compunha uma sequência de movimentos que revelava a sua autoria. Nesse caso, o improviso parecia assentar-se nas possibilidades de arranjos das microssequências, congregando as marcas da tradição e a contribuição específica daquele ator-dançarino ao compor a sua dança. Ainda sem a utilização da máscara, outra parte do treinamento foi destinada a cuidar dos detalhes, em que se buscou afinar o esboço construído, integrando-se, em seguida, o objeto. Tanto os exercícios específicos para a prática da dança quanto a dança propriamente dita eram, em determinados momentos, realizados com o praticante sentado numa cadeira.

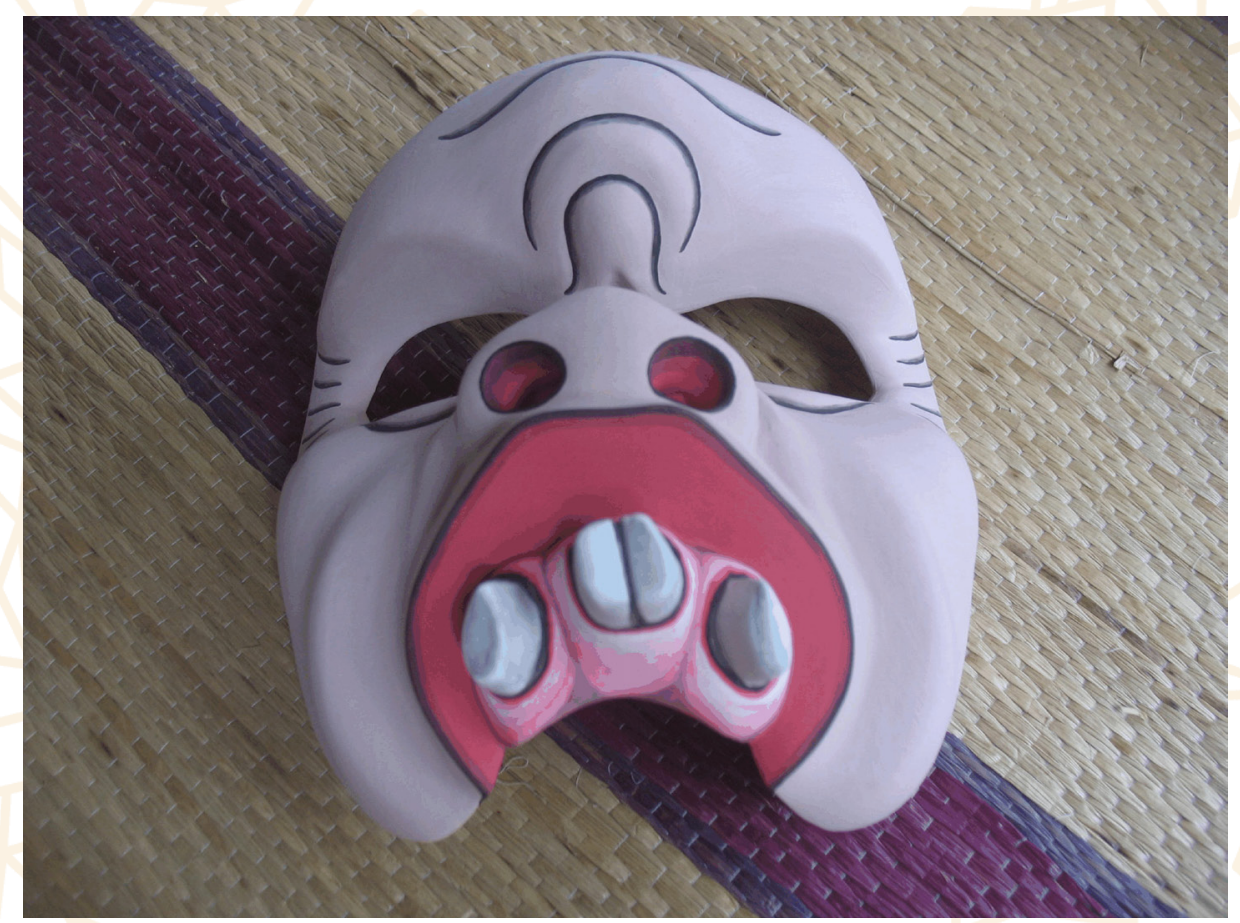

Bondres

Espaço e tempo são princípios fundamentais no trabalho com a máscara, quando pensada como um corpo em movimento. O espaço onde o corpo-máscara atua não permanece imune e é também um 'corpo' que interage com o atuante e o energiza a partir das relações estabelecidas com ele. O espaço cênico em que acontece o Topeng articula-se àquele sociorreligioso e traz em si suas direções axiais. Como observam Badem e de Boer (1989), a configuração axial kaja e kelod, um princípio de estruturação dos arranjos espaciais em Bali, abrange tanto os templos quanto os complexos residenciais. Esse eixo perfaz um descenso que parte da montanha (o plano alto é a morada dos deuses) em direção ao mar (o plano das entidades que habitam o mundo subterrâneo), e indica também o fluxo da água, elemento fundamental do Hinduísmo 
balinês, que serve para a purificação espiritual. O sistema de orientação montanha-mar inverte a perspectiva axial, conforme o lugar em que a edificação se situa. Transposto para o trabalho de corpo, esse percurso, elaborado no campo da imaginação, envia-nos à verticalidade e horizontalidade que organizam o corpo por meio do olhar que se torna o que vê, engajando o corpo no fluxo energético da respiração e da música interior das sensações, as quais decorrem das identificações com a matéria, contidas na prática com a máscara neutra.

O eixo transversal kagnin e kauh de orientação adota como referência o ciclo nascente-poente do sol. Da intersecção kaja-Kelod e Kagnin-kauh, resulta um espaço quadrangular ou retangular no qual as disposições das edificações devem ser pensadas. Assim, o templo familiar localiza-se na área considerada a mais sagrada do complexo, cuja orientação é kelod-kagnin. Retornando-se ao plano espacial retangular, observam-se ainda quatro direções intermediárias, situadas em cada quadrante. O equilíbrio dinâmico dessas direções envolve os níveis alto, intermédio e baixo e insere-se na concepção dual que perpassa a cultura balinesa, apresentando aspectos que escapam ao escopo deste artigo.

Quando dança, o ator não se orienta por apenas um lado ou uma perspectiva dessa configuração espacial, e explora a cena abarcando todas as direções. Portanto, por exemplo, nas práticas com o Topeng Tua, a dança se iniciava no sentido kaja (frente-montanha), virando-se ao Kangin (lado direito), depois Kauh (lado esquerdo), seguido pelo kelod (lado contrário ao Kaja), finalizando com o retorno à direção inicial. Gabo (2000) diz que "espaço e tempo são as únicas formas em que a vida é construída e que, portanto, a arte deve ser construída" (p. 32). Esta ideia, que foi endereçada, pelo autor, aos artistas-escultores, músicos, atores, poetas, fica bastante evidente quando vivenciada pelo corpo durante o exercício da partitura. As direções são linhas de força que dizem respeito não apenas à organização espacial da vida cotidiana, mas também à organização corporal num espaço cênico, o qual, entre outros aspectos, vincula-se à respiração como promotora do trânsito interno-externo da energia (bayu), potencializando a complexidade do evento. $O$ corpo se expande em todas as direções, a partir das linhas propulsoras do movimento (ação), e, como ocorre no Ai Ki Do, há o ponto do qual a energia irradia e flui em todo o ser.

$\mathrm{Na}$ presente experiência, em que se lidou com os movimentos visível e invisível, foi necessário reter e liberar a respiração (energia) quando em ação e, dessa 
forma, no Topeng Keras busquei, por exemplo, concentrar internamente a energia no momento em que efetuava a posição inicial (agem kiri), seguindo o fluxo controlado da respiração quando começava a me movimentar. Conforme observa I Nyoman Budi Artha $^{9}$, a noção de $n g u n d a$ bayu ${ }^{10}$ é fundamental para o ator-dançarino e refere-se, em síntese, à organização da energia, ou seja, de como conservá-la e distribuí-la por todo o corpo, de como mantê-la dentro de si ou deixá-la sair, ritmo que se constrói com o fluxo, a retenção, a pulsação e o sentimento.

Na constituição do corpo-figura, ou corpo-máscara, o conceito de taksu revela a busca de um estado energético que o torna pleno quando manifesto no corpo do ator-dançarino. Para Cokorda Swastika (2012), taksu fundamenta-se na ideia de sekala e niskala e porta o princípio dualístico, que se traduz na busca de um equilíbrio. Conforme Eiseman (1989), sekala e niskala são domínios que coexistem e podem ser traduzidos como visível e invisível e se aproximam da ideia ocidental de físico e espiritual. Niskala diz respeito àquilo "que não pode ser sentido diretamente, mas [a] o que pode ser sentido internamente" (1989, p. 127). Nesse sentido, mente e coração atuam num espaço-tempo sincrônico, provocando alteração energética no corpo, algo que aquece e se passa com ele. Taksu refere-se ainda à ação que congrega atividade e sentimento, simultaneamente. Para Djmat, taksu é o "Deus dentro de você", e o público percebe quando o dançarino atinge esse estado, manifestado pelo carisma interno (2012). Acrescenta ainda que o conceito diz respeito a tudo o que se faz, a algo bem executado ${ }^{11}$. Nesse sentido, o dançarino é um artesão que busca atingir a perfeita beleza da flor, o encontro das realidades visíveis e invisíveis pelo exercício do seu ofício, conectando-se ao cosmo divino. Deve-se observar que, para além das palavras com as quais intentamos circunscrevê-lo, taksu não distingue a vida da arte. Recorrendo a Gabo (2000), diria:

\footnotetext{
A arte [taksu] é chamada a acompanhar o homem em todos os lugares e em todas as circunstâncias em que sua vida inexaurível flui e age - no banco da fábrica, à mesa no trabalho, no descanso, no jogo, em dias de trabalho e nas férias, em casa e na rua - para que a ardente urgência de viver nunca se extinga na humanidade ${ }^{12}$ (p. 34).
}

\footnotetext{
${ }^{9}$ Anotação feita durante as práticas com I Nyoman Budi Artha, filho de Djimat, que ministrou aulas durante cerca de 10 dias em virtude da impossibilidade do pai devido a uma queda.

${ }^{10}$ Ngunda Bayu e taksu são conceitos que aparecem em diversos estudos sobre o teatro balinês, o que afirma a relevância de ambos para a constituição de estados corporais do ator-dançarino.

${ }^{11}$ Cokorda Swastika expressa, igualmente, essa mesma ideia.

12 Tradução do Professor Luiz Fernando Ramos.
} 
Nessa ambiência impregnada, a música também desempenha um papel fundamental e realiza, juntamente com a dança, uma simbiose no corpo do ator-dançarino, o qual exercita a escuta cíclica pelo ritmo e pela melodia que atravessa o seu corpo. $\mathrm{Na}$ estrutura musical/corporal do Topeng Tua, o som do gongo ${ }^{13}$ é o elemento que sinaliza cada passagem da sequência, cuja batida, a cada oito tempos, exerce uma força energética vibratória sobre o corpo. Como relata Palermo (2011), o ator-dançarino deve "tornar-se uno com a música", em outras palavras, "ser música" (p. 160), elaborando um jogo refinado e afinado com o Gamelan, criando uma sintonia imagética, uma sinfonia visível-invisível que brota na relação dos corpos: o ator-dançarino, os músicos e os seus instrumentos. Tal como a voz, a música emana uma substância corpórea que transparece invisível no espaço. Em nossas práticas, foi experimentado o estudo da partitura corporal tanto com a música gravada quanto, em alguns momentos, com a utilização do gangsa ${ }^{14}$, feito que promovia outra qualidade de interação, principalmente, quanto à escuta e à maleabilidade do tempo.

Na primeira parte do processo, trabalhou-se com o rosto descoberto, no qual todo o corpo convertia-se em máscara pela intencionalidade energética na composição de cada figura. Faziam parte dessa etapa exercícios corporais preparatórios envolvendo pontos de apoio, transferência de peso e articulação dos braços e das mãos. A dança balinesa possui, como característica, o fato de ser executada em abertura. Assim, um dos exercícios realizados consistia em colocar-se de pé na posição inicial (agem), primeiramente, com a força-peso na perna direita (agem kiri), flexionando-se, em seguida, os joelhos, passando-se para um plano médio. O próximo passo consistia em virar, num só golpe, o calcanhar para fora, mantendo-se o pé e a extensão da perna em rotação externa, elevando-se, na sequência, a perna direita até a altura do joelho da perna oposta, retornando-a à posição anterior. Por fim, transfere-se a força-peso para a perna esquerda para realizar o exercício partindo do agem kanan. A cada repetição, o exercício tornava-se mais complexo, chamando-se atenção para a manutenção da altura dos ombros, a organização da energia (bayu), a posição e os movimentos dos braços e das mãos, que devem estar relacionados com as direções dos movimentos das pernas, ou para a realização correta do tangki, ou seja, a transferência de um agem para outro. Além dos aspectos mencionados, a repetição

\footnotetext{
${ }^{13}$ Há dois tamanhos de gongo: o grande, tocado com a cabeça acolchoada da baqueta, e o pequeno, com o cabo.

${ }^{14}$ Gangsa - espécie de xilofone composto por barras de metal ou de bambu e ressonadores tubulares. Toca-se com um martelo de madeira.
} 
vincula-se à concentração, um absorver-se em si e, ao mesmo tempo, estar presente naquilo que se faz. Da mesma forma que, "por meio de concentrações repetidas e experiências com as máscaras, o ator Nô abre-se ao mundo invisível" (OLSEN, 2004, p. 10), o dançarino balinês se predispõe a essa experiência.

A dança não era algo abstrato, no sentido em que era uma espécie de vestimenta do personagem, da criação da figura. Portanto, dançar é manifestar a vida dessa entidade cênica. Aprender as coreografias das máscaras implica em imitar movimentos, repeti-los e memorizá-los corporalmente, um processo orgânico, no qual o sentimento (feeling), como diz Budi Artha, deve estar na base de toda a ação. Sentimento que irriga o movimento e o faz florescer. Como ressaltado, a organização do corpo na dança promove a caracterização de cada figura. Se, no Topeng Tua, os braços são elevados até a altura da linha dos ombros, no Keras exige-se elevação mais acentuada dos ombros e a extensão dos braços, em parte, decorrente do vigor característico exalado pela máscara.

Vestir a máscara põe em jogo o papel do figurino que, além de caracterizar o personagem, dialoga com as direções do espaço-tempo. Por exemplo, no Topeng Tua, os movimentos da capa reverenciam as divindades e os altares do templo, dialogam com o guarda-chuva (passagem denominada nyomak pajeng), são manipulados na sequência upak lantang ou servem a ações, tais como enxugar o suor do rosto ou assoar o nariz. Durante as nossas práticas, improvisávamos a vestimenta da figura com um sarong amarrado na altura do peito, com o qual tecíamos a 'coreografia do figurino'. É interessante observar que o traje, composto por sobreposição de peças, amplia e desnaturaliza o corpo e, geralmente, há a necessidade de outra pessoa para ajudar a vesti-lo. 0 figurino é uma espécie de base para a composição das figuras, realizada mediante a troca da máscara e do adereço da cabeça, considerada sagrada na cultura balinesa. $\mathrm{A}$ manipulação do figurino dialoga com o corpo, engendrando posturas e movimentos do olhar, da cabeça, das mãos e dos pés e da aura que o circunda.

Em Bali, homens usam flores na orelha durante os eventos cênicos. Nas máscaras, as flores colocadas, de cada lado, são artificiais e naturais. Isso representa uma mistura que demonstra o princípio dualístico, em que nada é tão absoluto, há sempre equilíbrio de polaridades, de um estado dinâmico que deve ser sustentado: vida e morte, keras e manis, rígido e flexível, kaja e kelod e céu e terra. Zeami (1999), quando aborda a constituição do teatro Nô, diz que "a flor é a vida do Nô (p. 120)" e 
acrescenta: "se quiser conhecer a flor, primeiro, há que conhecer a semente. A flor será o coração e as sementes serão as técnicas” (p. 126). Para alcançar a flor, há um caminho a ser trilhado: existem aquelas que emergem das condições físicas, trabaIhando-se a voz, o corpo e a graça, mas a verdadeira flor está gravada no coração.

Em Bali, homens usam flores na orelha como parte da vivência cotidiana. São chamadas a acompanhar o homem em todos os lugares e em todas as circunstâncias em que sua vida inexaurível flui e age - nos templos, à mesa, no descanso, no jogo, em dias de trabalho, em casa e na rua, nos aromas que rescindem das oferendas postas em toda a cidade, no chão, destinadas a buta e kala, nos altares, nas árvores envoltas com tecidos quadriculados, nas encruzilhadas. A flor na orelha é a imagem do transitório e do perene, que se revela nas ações sempre renovadas, um corpo que exala o seu perfume misturado aos cheiros da cidade.

Os mesmos homens envolvem o secular, o sobrenatural e o religioso, como também, Sidakharya, a máscara que porta um cudamani (símbolo de realeza) na testa, que encerra o ciclo do Topeng Pajegan, expressando um sorriso que abraça todos e finaliza o ato oferecendo água, flores, arroz, moedas e incenso. O trabalho foi feito! Figura que galvaniza o olhar das crianças, que acorrem ao seu encontro e brincam numa atmosfera em que o cômico-profano e o sagrado se interpenetram, se defrontam e buscam equilíbrio. Um leve sorriso de criança que também emerge na fisionomia do Topeng Tua. A infância é o estado-máscara por excelência, é a floração de todas as possibilidades. A flor é uma imagem que sinaliza a escuta gravada no coração de quem veste essas entidades.

Como diz Bandem e de Boer (1995), “máscaras tenget são 'magicamente perigosas' (p. 152)", porém, nem todas detêm essa qualidade sobrenatural. Um objeto tenget mantém seu poder permanentemente, assim, uma máscara que o possui emana força e permanece viva independentemente de ser usada. Quando o dançarino coloca tal máscara, essa potência adentra em seu ser e é manifesta no corpo. Segundo Eiseman (1995, p. 208), mesmo uma máscara comum pode se tornar tenget se estiver em posse do dono por um longo tempo e se ele fizer regularmente oferendas a ela (1995, p. 209). É provável que essa força contida no objeto resida também no corpo como energia que permanece actante, resultado da convivência com a máscara, como o perfume que exala do frangipani - árvore do templo. 


\section{Referências bibliográficas}

BANDEM, I. M.; de BOER, F. E. Kaja and Kelod: Balinese Dance in Transition. Kuala Lumpur: Oxford Press, 1989.

CATRA, I. N. Penasar: a central mediator in Balinese dance drama-theatre. PhD thesis. Middletown (CT): Wesleyan University, 2005.

DJIMATI, I.M. Entrevista realizada em Batuan (Bali), Jan. 2012.

EISEMAN, F. B. Jr. Bali: Sekala and Niskala, vol. 2: essays on tradition, society and craft. Berkeley: Periplus edition, 1990.

\section{edition, 1989.}

Bali: Sekala and Niskala, vol. 1: essays on religion, ritual and art. Berkeley: Periplus

GABO, N. Gabo on Gabo. Suffolk (Eng.): Bookworks, 2000.

LECOQ, J. Le corps poetique - Un enseignement de la création théâtrale. En colaboration avec Gabriel Carasso et Jean-Claude Lallias. Paris: Actes Sud-Papiers, 1997.

OLSEN, M. As máscaras do Buda dourado. São Paulo: Perspectiva, 2004.

PALERMO, C. Respirando para dentro da máscara: o corpo toma forma no teatro dança balinês - uma experiência de aprendizado. In: BELTRAME, V.; ANDRANDE, M. (Org.) Teatro de Máscaras. Florianópolis: UDESC, 2011. Págs. 153-166

STORARO, V. Claro.Escuro. In: Folha de São Paulo, Caderno Mais! 25 mai 2008, p. 4 (Entrevista a Andréia Muncini).

SWASTIKA, C. Entrevista realizada em Ubud (Bali). Fev, 2012

ZEAMI, F. Tratado sobre las prácticas del teatro Nó y quatro dramas Nó. Madrid: Editorial Trotta, 1999. 